\title{
Discovery of a novel cystathionine-beta-synthase mutation and diagnosis of homocystinuria by whole exome sequencing in a family from rural Honduras
}

\author{
Scott A. Turner ${ }^{1}$, Mary Beth P. Dinulos ${ }^{2,}{ }^{3}$, Stephanie E. Vallee ${ }^{2,}{ }^{3}$, Linda Kennedy ${ }^{4}$, Peter Mason ${ }^{5}$, \\ Dean Seibert ${ }^{5}$, Marco Tulio Martinez ${ }^{4}$, Heather B. Steinmetz ${ }^{2}$, Gregory J. Tsongalis ${ }^{1,2,4}$, J oel A. \\ Lefferts $^{1,2}$
}

1. Department of Pathology, Geisel School of Medicine at Dartmouth, Hanover, NH, USA. 2. Department of Pathology, Dartmouth-Hitchcock Medical Center, Lebanon, NH, USA. 3. Department of Pediatrics, Dartmouth-Hitchcock Medical Center, Lebanon, NH, USA. 4. Norris Cotton Cancer Center, Geisel School of Medicine at Dartmouth, Hanover, NH, USA.

5. Department of Medicine, Geisel School of Medicine at Dartmouth, Hanover, NH, USA.

Correspondence: Scott A. Turner. Address: Dartmouth-Hitchcock Medical Center, 1 Medical Center Drive, Department of Pathology, HB 7600, Lebanon NH, 03756, USA. E-mail: scott.a.turner@dartmouth.edu

Received: February 24, 2015

Accepted: March 25, 2015

Online Published: April 17, 2015

DOI : $10.5430 /$ crcp.v2n3p59

URL: http://dx.doi.org/10.5430/crcp.v2n3p59

\section{Abstract}

Objective: Lack of newborn screening, limited access to healthcare, and complex presentation has resulted in gross under-diagnosis of in-born metabolism disorders in many Central American countries. In this study we describe the use of advanced clinical genomics to identify a novel cystathionine-beta-synthase (CBS) mutation with limited clinical information from a small highly consanguineous indigenous community in rural Honduras.

Methods: We performed chromosomal microarray analysis and whole exome sequencing on three affected siblings and their mother. Confirmatory Sanger sequencing for CBS exon 10 was performed on genomic DNA from extended family within the community.

Results: We identified a novel homozygous missense mutation (p.Tyr308Thrfs*11) in CBS that resulted in the diagnosis of homocystinuria in three siblings. Patients were nonresponsive to standard pyridoxine treatment. We discovered an elevated coefficient of inbreeding $(\mathrm{F} \geq 0.20)$ suggestive of an unreported highly consanguineous population. Genotyping identified $\sim 47 \%$ of extended family as carriers of this novel mutation.

Conclusion: Expanded use of whole exome sequencing from buccal cell genomic DNA allowed for the discovery of a novel mutation resulting in a rare recessive disorder in an isolated under-served population. Clinical phenotypes and treatment response of patients with this novel homozygous mutation add to our clinical understanding of homocystinuria.

\section{Key words}

Homocystinuria, Cystathionine-beta-synthase, Pyridoxine, Consanguinity

\section{I ntroduction}

Lack of newborn screening programs and limited access to healthcare in the low-resource Latin American countries of Honduras, El Salvador, and Haiti have resulted in the gross under-diagnosis of inherited metabolic disorders ${ }^{[1,2]}$. Founder 
mutations in isolated rural communities can further complicate this problem. Diagnosis confirmation for these disorders may involve collection and transportation of specimens for chemical and genetic testing that can be problematic for rural clinics. While buccal swabs can improve access to genetic testing, limited physical examination and lack of communication with testing labs decreases the probability of a successful diagnosis.

Homocystinuria (MIM \#236200) is a rare recessively inherited in-born amino acid metabolic disorder that results in elevated plasma homocysteine (Hcy) concentrations and amino acid toxicity. Elevated Hcy results from a deficiency in the enzyme cystathionine-beta-synthase (CBS, EC 4.2.1.22), which is responsible for the transsulfuration of homocysteine to cystathionine and cysteine during methionine metabolism ${ }^{[3]}$. Worldwide frequency estimates range from 1:65,000 to $1: 900,000{ }^{[4]}$, but rates as high as 1:1,800 have been reported in highly consanguineous populations ${ }^{[5]}$. To date over 160 pathogenic variants have been identified in the CBS gene (http://cbs.lf1.cuni.cz/mutations.php). Common variants display distinct regional and ethnic distributions, including c.833T $>$ C (p.Ile287Thr) in eastern Europe ${ }^{[6]}$, c.919G $>$ A (p.Gly307Ser) in Ireland ${ }^{[7]}$, and c.572C $>$ T (p.Thr191Met) in Iberian Peninsular and Colombian populations ${ }^{[8]}$ and are commonly targeted in screening of at-risk populations. Additional rare or novel CBS mutations are typically isolated to individual communities and identified through sequencing following a complete clinical workup ${ }^{[9]}$.

Here we describe the challenges of diagnosing homocystinuria in patients from an isolated rural Honduran community. A complex clinical presentation and uncertain diagnosis required clinical chromosomal microarray analysis and whole exome sequencing to successfully identify a novel CBS frameshift mutation, p.Tyr308Thrfs*11(c.921delC), in three siblings.

\section{Methods}

\subsection{Subjects}

Study subjects were identified through an outreach clinic to a rural community of the indigenous Honduran Tolipani tribe, consisting of approximately 25 households with two surnames. The proband, a 14-year-old female, presented with presumed lenticular displacement. Her 11-year-old brother presented with pronounced genu valgum and muscle weakness. Both were reportedly normal at birth, but now demonstrate marked cognitive dysfunction. Their 4-year-old sister appears to be physically and developmentally normal. Buccal cells were obtained from these three siblings, the unaffected mother, and 35 additional second and third degree relatives. A pedigree was obtained at time of sample collection but some of the reported relationships may not be biologic.

\subsection{Genetic testing}

DNA was isolated from buccal swabs using QIAGEN Puregene Buccal Cell Core Kit according to manufacturer instructions and quantified using a NanoDrop spectrophotometer.

Microarray analysis was done using CytoScanHD Array (Affymetrix, Santa Clara, CA) and Chromosomal Analysis Suite (ChAS) v1.2 (Affymetrix) software. Percent autosomal homozygosity was calculated using long contiguous stretches of homozygousity (LCSH) at least $3.0 \mathrm{Mb}$ in size. Autozygosity mapping to identify recessive disorder genes was performed with the Genomic Oligoarray and SNP array evaluation tool v2.0 ${ }^{[10]}$.

Augmented whole exome sequencing (WES) was performed using the ACE Clinical Exome ${ }^{\mathrm{TM}}$ (Personalis, Inc., Menlo Park, CA). WES data was analyzed and variant calls made by using their ACE Exome pipeline and knowledge-based variant ranking system.

Confirmatory Sanger sequencing of CBS exon 10 used standard v3.1 Big-Dye Terminator methods and the ABI 3500 automated sequencer (Applied Biosystems). Traces were aligned to CBS (NM_000071) and visualized using SeqScape Software v2.7 (Applied Biosystems). 


\subsection{Total homocysteine testing}

Defects in methionine metabolism were tested via measurement of total homocysteine collected on a dried blood spot (DBS) card and Liquid Chromatography-Tandem Mass Spectrometry at Mayo Medical Laboratories (Rochester, MN) as described previously ${ }^{[11]}$.

\section{Results}

While chromosome microarray analysis revealed no clinically relevant copy number variants, the numerous long contiguous stretches of homozygosity (LCSHs) were detected throughout the genome of all three siblings are suggestive of identity by descent, as shown in Figure 1 . A coefficient of inbreeding $(F) \geq 0.20$ was calculated based on autosomal LCSHs including $711 \mathrm{Mb}$ (mean size of $9.6 \mathrm{Mb}$ ), $772 \mathrm{Mb}$ (mean size of $9.6 \mathrm{Mb}$ ), and $567 \mathrm{Mb}$ (mean size of $8.5 \mathrm{Mb}$ ) for the proband, and her two siblings respectively. The unaffected mother had an $F$ value of 0.218 (673 Mb of LCSHs, mean of $8.7 \mathrm{Mb}$ ) suggesting a highly homogenous population. Autozygosity mapping identified over 200 genes associated with autosomal recessive diseases in LCSH regions common to siblings. The number of candidates was reduced to 45 genes by excluding regions of overlapping maternal LCSHs.

Figure 1. Large contiguous stretches of homozygosity (LSCH) indicate increased probability of autosomal recessive disorder. A) Allele tracks for patients and mother indicating Log2 ratios, allele peaks (MAF) and regions of loss of heterozygosity in Chr21: q22.3 which contains the CBS gene. B) Percentage of autosomal genome containing LCSH compared to the genome of an unrelated individual residing outside of the affected community.

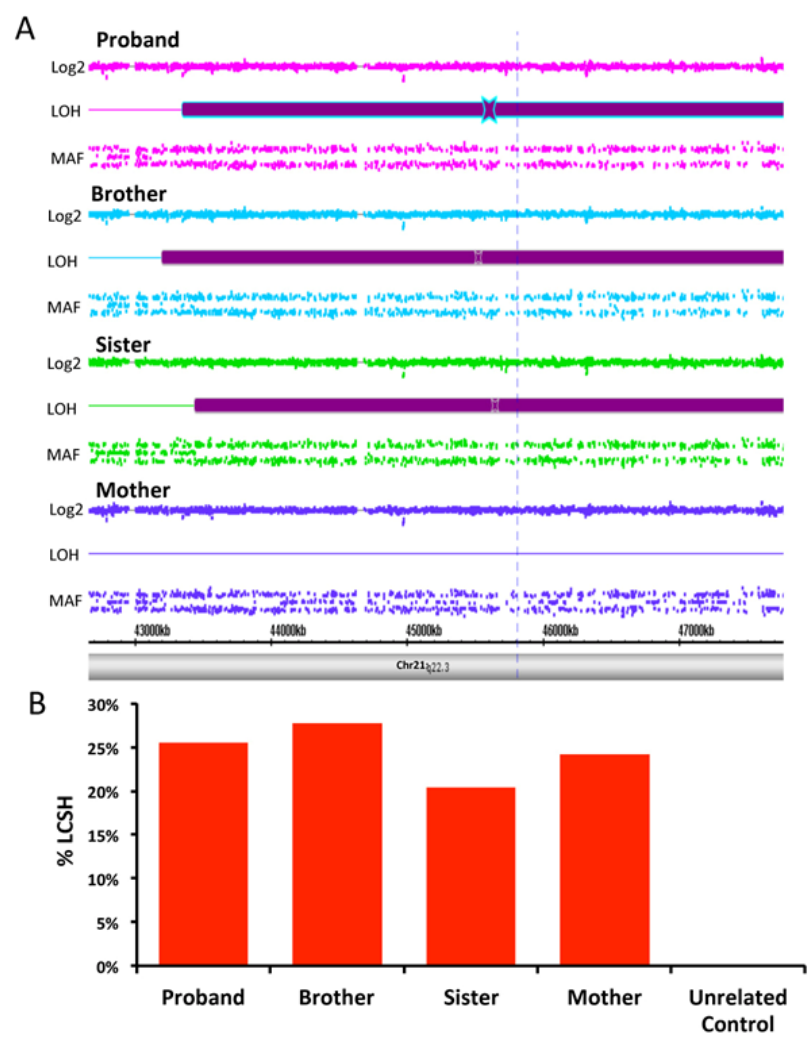

To avoid a potentially lengthy gene-by-gene sequencing approach to reach a diagnosis for these siblings, WES was performed on the proband and it identified over 200,000 genomic variants (see Table 1). Filtering eliminated low quality variants, common variants ( $\mathrm{AF}>1 \%$ ), and variants that deviated from expected inheritance patterns leaving 1141 variants for interpretation. Associated genes were ranked according to known clinical phenotypes reveling two potentially pathogenic homozygous variants, c.921delC (p.Tyr308Thrfs*11) in CBS and c.6044T >C (p.Phe2015Ser) in EPG5, homocystinuria and Vici syndrome, respectively. Of note, CBS is located in LCSHs of all three siblings but not their mother. EPG5 is located within a LCSH in the proband, but no LCSHs were detected surrounding this gene in her siblings or mother. 
Homozygosity for the p.Tyr308Thrfs*11(c.921delC) variant was confirmed for the proband and genotypes for her siblings, mother and 35 second- and third-degree relatives were obtained (see Figure 2). Homozygous deletions were confirmed in two siblings, and the mother's carrier status confirmed by heterozygosity of c.921delC. The deletion was tracked back to the maternal grandmother and an additional $62 \%(13 / 21)$ of the maternal second- and third-degree relatives tested were heterozygous for the deletion. Testing on the reported father was unavailable due to unrelated death. Access to paternal family members was also limited, however $11 \%$ (1/9) of those tested were heterozygous for the deletion. Only one of the father's first-degree relatives (II.1) tested positive for the c.921delC.

Table 1. Whole exome sequence variant filtering for autosomal variants identified in probrand (total variants: 200,610)

\begin{tabular}{lll}
\hline & Autosomal Dominant & Autosomal Recessive \\
\hline Inheritance Pattern Consistent Variants & 770 & 434 \\
Variants in candidate genes & 54 & 26 \\
Matches after manual review & 0 & 2 \\
\hline
\end{tabular}

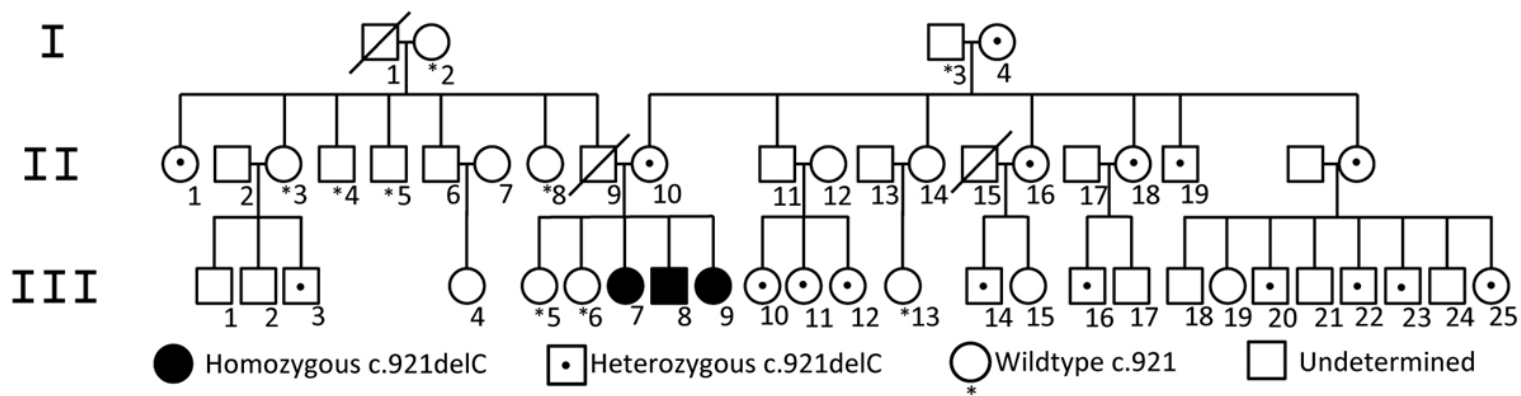

Figure 2. Inheritance pattern of CBS p.Tyr308Thrfs*11 (c.921delC) mutation in three generation of an indigenous Honduran family. Carrier status was traced back to maternal grandmother (I.4) and present in all subsequent generation. Relationships are depicted as reported by family however high levels of consanguinity suggest a complex family history not described. Described proband is represented as III.7 in pedigree.

Dried blood spot testing confirmed homocysteine levels at least $8 \mathrm{X}$ greater than that of the reference value $(>120 \mathrm{nmol} / \mathrm{ml}$, reference value $<15 \mathrm{nmol} / \mathrm{ml}$ ) for all three patients. It was noted that while well above the normal range the youngest patient had lower homocysteine levels $(121.5 \mathrm{nmol} / \mathrm{ml})$ compared to her affected siblings $(>180 \mathrm{nmol} / \mathrm{ml})$. There are many possible explanations for this variation including accumulation of homocysteine with age and dietary alterations prior to testing. Patients were put on standard pyridoxine (vitamin B6) treatment to reduce serum homocysteine concentrations and homocysteine levels were reevaluated after twelve weeks of treatment. All three patients failed to show a significant reduction in homocysteine level post-treatment as shown in Table 2. Upon retesting results showed that the amount of homocysteine in the blood of the youngest patient was similar to that of the other affected siblings.

Table 2. Homocysteine levels in blood pre-treatment and following 12 weeks of pyridoxine treatment

\begin{tabular}{llll}
\hline Patient ID & Homocysteine levels pre-treatment & Homocysteine levels 12 weeks of treatment & Reference Value \\
\hline Proband & $187.0 \mathrm{nmol} / \mathrm{ml}$ & $162.7 \mathrm{nmol} / \mathrm{ml}$ & $<15.0 \mathrm{nmol} / \mathrm{ml}$ \\
Brother & $193.3 \mathrm{nmol} / \mathrm{ml}$ & $150.3 \mathrm{nmol} / \mathrm{ml}$ & \\
Sister & $121.5 \mathrm{nmol} / \mathrm{ml}$ & $158.9 \mathrm{nmol} / \mathrm{ml}$ & \\
\hline
\end{tabular}

\section{Discussion}

This paper is the first to describe the clinical manifestation and treatment response of a novel c.921delC pathogenic variant in the CBS gene resulting in homocystinuria. In addition, we describe the utility of using advanced genomic diagnostics to identify an inherited metabolic disorder using this limited clinical information in a family from the low-resource country of Honduras. 
While the diagnosis of homocystinuria is made through newborn screening and mutations identified by gene level sequencing in most areas of the world, those born in isolated regions of some under-developed countries have little chance for early diagnosis and treatment ${ }^{[1]}$. A diagnosis of homocystinuria missed during newborn screening is compounded by diverse clinical manifestations and limited access to clinics with adequate testing and radiological equipment. The phenotype reported in these patients (i.e. developmental delay, skeletal deformities) did not indicate a particular disease. Buccal swabs allowed for extended storage and shipment at ambient temperature, giving these patients access to sophisticated genetic testing. The lack of on-site resources and readily available clinical information meant that genome-wide testing was the only viable option for diagnosis.

The use of chromosomal microarray and whole exome sequencing for clinical diagnosis of Mendelian disorders has now been well established ${ }^{[12,13]}$. While genomic approaches provide significant ethical and technical challenges, they are often the most successful option for determining the basis of genetic disease in patients with overlapping differential diagnoses and non-specific presentation. CMA has a reported diagnostic yield of $15 \%-20 \%$ in patients with developmental disabilities and congenital anomalies ${ }^{[12]}$ and is capable of gene-level copy number resolution for diagnoses of genetics disorders. Although no pathogenic CNVs were detected, this analysis provided insight into a complicated and incomplete record of family history highlighting the probability of an autosomal recessive disorder. High percentages of LCSH are suggestive of high levels of consanguinity unreported by the family. Reported percentages of consanguineous marriages in Central America, including Honduras, are low when compared to Middle-Eastern populations that have documented increases in autosomal recessive diseases, such as homocystinuria ${ }^{[14,15]}$. It was therefore surprising to find the coefficient of inbreeding consistent with consanguineous first-degree pairings. The mean size of LCSH in these individuals was approximately $9 \mathrm{Mb}$ while known cases of such pairings are typically much higher $(>20 \mathrm{Mb})$ suggesting repeated inbreeding events over numerous generations reducing LCSH size but maintaining high consanguinity ${ }^{[16]}$. In addition, carrier status observed in one paternal cousin (III.3) but not her mother (II.3), who is a reported paternal sibling, provides additional evidence of consanguinity. The father of this child (II.2) is not reported to be a first-degree relative and was unavailable for genetic testing, however it is likely that he is a carrier for the c.921delC variant. This result coupled with the high LCSH levels observed in both generations is suggestive of wider spread consanguinity in this community. High levels of consanguinity dramatically increase the risk for inheritance of autosomal recessive disorders ${ }^{[17]}$. While autozygosity mapping is often used to narrow down the autosomal recessive disorder causing loci the total number of candidate genes remaining in this case made single gene analysis highly unpractical.

Genetic diagnosis by whole exome sequencing has a demonstrated success rate of $25 \%$ in cases of intellectual disabilities or other neurological findings ${ }^{[13]}$. In addition, autosomal recessive disorders resulting from the inheritance of two inactivating point mutations make WES ideal for cases where pathogenic variants are suspected but the disorder unknown. Interrogation for pathogenic variations across all these genes simultaneously increases the probability of a successful diagnosis. Two potentially pathogenic variants identified by WES were examined further for overlapping phenotypes observed in these patients. The p.Phe2015Ser EPG5 variant is atypical of pathogenic variants in Vici syndrome. All known rare syndromic variants in this gene are nonsense or frameshift mutations while the p.Phe2015Ser results in missense mutation and does not likely result in similar loss of protein. Many of the defining and more severe phenotypes (early childhood mortality, cleft palate, and variable immunodeficiency) were not present in these patients ${ }^{[18]}$. CMA analysis also showed the LCSH containing EPG5 was not present in all three patients eliminating Vici syndrome as a potential diagnosis.

The novel c.921delC CBS variant results in a frameshift and early termination of the CBS transcript. This variant is located within the CBS catalytic domain responsible for binding pyridoxal 5'-phospate (PLP) and lies in the entry to the active site responsible for Hcy binding. Common pathogenic homocystinuria variants in neighboring residues (Gly305 and Gly307) have been found to abolish homocysteine binding, blocking the transsulfrration pathway and increasing Hcy levels ${ }^{[19]}$. Additionally, the c.921 delC frameshift mutation results in a premature stop codon at amino acid 319 completely eliminating the regulatory domain (421-543) and potentially allowing for nonsense-medicated decay. Interestingly, yeast 
models have shown that loss of the regulatory domain alone results in a "superactivated" enzyme potentially reversing the effects of other homocystinuria causing mutations ${ }^{[20]}$. However this superactivation has yet to be observed in published human variants and a loss of Hcy binding in the Tyr308Thr variant could explain the elevated levels of Hcy. A complete biochemical analysis of the c.921delC variant is needed to provide insight into the mechanisms of this CBS deficiency.

Large-scale genomic analysis is fast becoming a first-line test for the diagnosis of genetic disease. In this case where traditional clinical testing and extensive clinical work-up was unavailable, this approach was the only viable option for successful diagnosis. By taking this gene-first approach to identifying a novel pathogenic variant, we were able to better direct limited resources in this community. Furthermore, genetic counseling provides a greater understanding of the risks of inheriting homocystinuria, allowing clinicians to identify and treat patients prior to the onset of preventable phenotypes. As costs continue to drop and availability increases for large-scale genomic analysis, patients in under-served and underresourced communities will have an improved opportunity for diagnosis using specimens such as buccal swabs which can be self-collected and easily transported for genetic or genomic testing.

\section{References}

[1] Borrajo GJ. Newborn screening in Latin America at the beginning of the 21st century. Journal of inherited metabolic disease. 2007; 30(4): 466-81. Epub 2007/08/19. PMid: 17701285. http://dx.doi.org/10.1007/s10545-007-0669-9

[2] Solanki KK. Training programmes for developing countries. Journal of inherited metabolic disease. 2007; 30(4): 596-9. Epub 2007/07/24. PMid: 17643196. http://dx.doi.org/10.1007/s10545-007-0680-1

[3] Mudd SLH, Kraus JP. Disorders of transsulfuration. In: Scriver, C., Beudet A. Sly, W., Valle, D., Childs, B., Kinzler, K., Vogelstien, B. (Eds.) The metabolic \& molecular bases of inherited disease. New York: McGraw-Hill; 2001.

[4] Janosik M, Sokolova J, Janosikova B, et al. Birth prevalence of homocystinuria in Central Europe: frequency and pathogenicity of mutation c.1105C > T (p.R369C) in the cystathionine beta-synthase gene. The Journal of pediatrics. 2009; 154(3): 431-7. Epub 2008/10/28. PMid: 18950795. http://dx.doi.org/10.1016/j.jpeds.2008.09.015

[5] Zschocke J, Kebbewar M, Gan-Schreier H, et al. Molecular neonatal screening for homocystinuria in the Qatari population. Human mutation. 2009; 30(6): 1021-2. Epub 2009/04/17. PMid: 19370759. http://dx.doi.org/10.1002/humu.20994

[6] Skovby F, Gaustadnes M, Mudd SH. A revisit to the natural history of homocystinuria due to cystathionine beta-synthase deficiency. Molecular genetics and metabolism. 2010; 99(1): 1-3. Epub 2009/10/13. PMid: 19819175. http://dx.doi.org/10.1016/j.ymgme.2009.09.009

[7] $\mathrm{Hu} \mathrm{FL}, \mathrm{Gu} \mathrm{Z}$, Kozich V, et al. Molecular basis of cystathionine beta-synthase deficiency in pyridoxine responsive and nonresponsive homocystinuria. Human molecular genetics. 1993; 2(11): 1857-60. Epub 1993/11/01. PMid: 7506602.

[8] Urreizti R, Asteggiano C, Bermudez M, et al. The p.T191M mutation of the CBS gene is highly prevalent among homocystinuric patients from Spain, Portugal and South America. Journal of human genetics. 2006; 51(4): 305-13. Epub 2006/02/16. PMid: 16479318. http://dx.doi.org/10.1007/s10038-006-0362-0

[9] Porto MP, Galdieri LC, Pereira VG, et al. Molecular analysis of homocystinuria in Brazilian patients. Clinica chimica acta; international journal of clinical chemistry. 2005; 362(1-2): 71-8. Epub 2005/07/05. PMid: 15993874. http://dx.doi.org/10.1016/j.ccen.2005.05.030

[10] Wierenga KJ, Jiang Z, Yang AC, et al. A clinical evaluation tool for SNP arrays, especially for autosomal recessive conditions in offspring of consanguineous parents. Genetics in medicine: official journal of the American College of Medical Genetics. 2013; 15(5): 354-60. Epub 2012/10/27. PMid: 23100014. http://dx.doi.org/10.1038/gim.2012.136

[11] Turgeon CT, Magera MJ, Cuthbert CD, et al. Determination of total homocysteine, methylmalonic acid, and 2-methylcitric acid in dried blood spots by tandem mass spectrometry. Clinical chemistry. 2010; 56(11): 1686-95. Epub 2010/09/03. PMid: 20807894. http://dx.doi.org/10.1373/clinchem.2010.148957

[12] Miller DT, Adam MP, Aradhya S, et al. Consensus statement: chromosomal microarray is a first-tier clinical diagnostic test for individuals with developmental disabilities or congenital anomalies. American journal of human genetics. 2010; 86(5): 749-64. Epub 2010/05/15. PMid: 20466091. http://dx.doi.org/10.1016/j.ajhg.2010.04.006

[13] Yang Y, Muzny DM, Reid JG, et al. Clinical whole-exome sequencing for the diagnosis of mendelian disorders. The New England journal of medicine. 2013; 369(16): 1502-11. Epub 2013/10/04. PMid: 24088041. http://dx.doi.org/10.1056/NEJMoa1306555 
[14] Hamamy H, Antonarakis SE, Cavalli-Sforza LL, et al. Consanguineous marriages, pearls and perils: Geneva International Consanguinity Workshop Report. Genetics in medicine: official journal of the American College of Medical Genetics. 2011; 13(9): 841-7. Epub 2011/05/11. PMid: 21555946. http://dx.doi.org/10.1097/GIM.0b013e318217477f

[15] Zaidi SH, Faiyaz-Ul-Haque M, Shuaib T, et al. Clinical and molecular findings of 13 families from Saudi Arabia and a family from Sudan with homocystinuria. Clinical genetics. 2012; 81(6): 563-70. Epub 2011/04/27. PMid: 21517828. http://dx.doi.org/10.1111/j.1399-0004.2011.01690.x

[16] Woods CG, Cox J, Springell K, et al. Quantification of homozygosity in consanguineous individuals with autosomal recessive disease. American journal of human genetics. 2006; 78(5): 889-96. Epub 2006/04/28. PMid: 16642444. http://dx.doi.org/10.1086/503875

[17] Modell B, Darr A. Science and society: genetic counselling and customary consanguineous marriage. Nature reviews Genetics. 2002; 3(3): 225-9. Epub 2002/04/25. PMid: 11972160. http://dx.doi.org/10.1038/nrg754

[18] Finocchi A, Angelino G, Cantarutti N, et al. Immunodeficiency in Vici syndrome: a heterogeneous phenotype. American journal of medical genetics Part A. 2012; 158A(2): 434-9. Epub 2011/10/04. PMid: 21965116. http://dx.doi.org/10.1002/ajmg.a.34244

[19] Meier M, Oliveriusova J, Kraus JP, et al. Structural insights into mutations of cystathionine beta-synthase. Biochimica et biophysica acta. 2003; 1647(1-2): 206-13. Epub 2003/04/11. PMid: 12686134.

[20] Shan X, Kruger WD. Correction of disease-causing CBS mutations in yeast. Nature genetics. 1998; 19(1): 91-3. Epub 1998/05/20. PMid: 9590298. http://dx.doi.org/10.1038/ng0598-91 